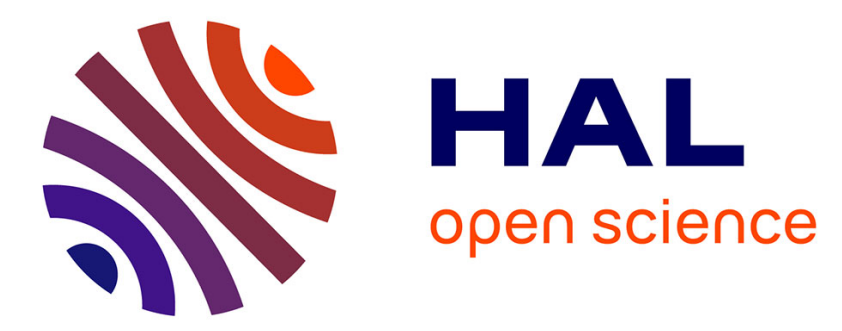

\title{
Estimation of the furan contamination across the Belgian food chain
}

Georges Scholl, Marie-Louise Scippo, Gauthier Eppe, Edwin de Pauw, Claude Saegerman

\section{- To cite this version:}

Georges Scholl, Marie-Louise Scippo, Gauthier Eppe, Edwin de Pauw, Claude Saegerman. Estimation of the furan contamination across the Belgian food chain. Food Additives and Contaminants, 2011, pp.1. 10.1080/19440049.2011.635158 . hal-00761690

\section{HAL Id: hal-00761690 https://hal.science/hal-00761690}

Submitted on 6 Dec 2012

HAL is a multi-disciplinary open access archive for the deposit and dissemination of scientific research documents, whether they are published or not. The documents may come from teaching and research institutions in France or abroad, or from public or private research centers.
L'archive ouverte pluridisciplinaire HAL, est destinée au dépôt et à la diffusion de documents scientifiques de niveau recherche, publiés ou non, émanant des établissements d'enseignement et de recherche français ou étrangers, des laboratoires publics ou privés. 


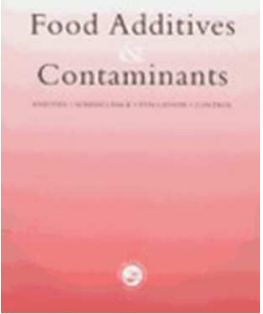

\section{Estimation of the furan contamination across the Belgian food chain}

\begin{tabular}{|c|c|}
\hline Journal: & Food Additives and Contaminants \\
\hline Manuscript ID: & TFAC-2011-218.R1 \\
\hline Manuscript Type: & Original Research Paper \\
\hline Date Submitted by the Author: & 14-Oct-2011 \\
\hline Complete List of Authors: & $\begin{array}{l}\text { Scholl, Georges; University of Liege, CART } \\
\text { Scippo, Marie-Louise; University of Liege, CART } \\
\text { Eppe, Gauthier; University of Liege, CART } \\
\text { de pauw, edwin; Liege University, Chemistry } \\
\text { Saegerman, Claude; University of Liege, Faculty of Veterinary Medecine, } \\
\text { Department of Infectious and Parasitic Diseases, Epidemiology and Risk } \\
\text { analysis applied to Veterinary sciences }\end{array}$ \\
\hline Methods/Techniques: & Exposure assessment \\
\hline Additives/Contaminants: & Process contaminants \\
\hline Food Types: & Baby food, Coffee, Meat, Processed foods \\
\hline Abstract: & $\begin{array}{l}\text { The current paper provides the estimate of the furan content in Belgian } \\
\text { foods. The objective of the study was to achieve the best food chain } \\
\text { coverage with a restrictive number of samples }(n=496) \text {. The geographic } \\
\text { distribution, the different market chains and labels, but also the } \\
\text { consumption frequencies were taken into account for the sampling plan } \\
\text { construction. Weighting factors on contamination levels, consumption } \\
\text { frequency and diversity of food items were applied to set up the model. } \\
\text { The very low detection capabilities (CC } \beta \text { ) of the analytical methods used } \\
\text { (sub-ppb) allowed reporting } 78.2 \% \text { of the overall dataset above CC } \beta \text { and, } \\
\text { in particular, } 96.7 \% \text { for the baby food category. The highest furan levels } \\
\text { were found in powder roasted bean coffee }(1912 \mu \mathrm{g} / \mathrm{kg}) \text { with a mean value } \\
\text { of } 756 \mu \mathrm{g} / \mathrm{kg} \text { for this category. Prepared meat, pasta and rice, breakfast } \\
\text { cereals, soups and baby food also showed high mean furan content ranging } \\
\text { from } 16 \text { to } 43 \mu \mathrm{g} / \mathrm{kg} \text {. Comparisons with contamination surveys carried out } \\
\text { in other countries pointed out differences for the same food group and } \\
\text { therefore contamination levels are related to the geographical origin of } \\
\text { food items. }\end{array}$ \\
\hline
\end{tabular}




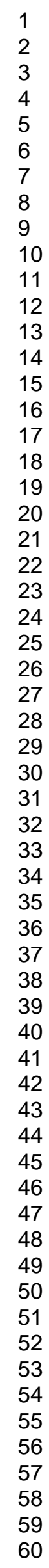

SCHOLARONE ${ }^{\text {w }}$

Manuscripts

7

.

10

11

12

13

14

16

17

18

19

20

22

23

25

26

27

29

30

32

33

34

35

36

38

39

40

41

43

44

45

46

47

48

50

51

52

54

55

58

59

60

http://mc.manuscriptcentral.com/tfac Email: fac@tandf.co.uk 
1 Estimation of the furan contamination across the Belgian food chain

2

3 Scholl Georges $^{1 \& 2}$, Scippo Marie-Louise ${ }^{4}$, DePauw Edwin ${ }^{2}$, Eppe Gauthier ${ }^{3}$, Saegerman

4 Claude $^{1}$

5

$6{ }^{1}$ Research Unit in Epidemiology and Risk Analysis applied to veterinary sciences (UREAR),

7 Faculty of Veterinary Medicine, University of Liège, Boulevard de Colonster 20, B-42 Sart-

8 Tilman, B-4000 Liege, Belgium

9

$10{ }^{2}$ CART, Mass Spectrometry Laboratory, Chemistry Department, University of Liege, Allée de

11 la Chimie 3, B-6c Sart-Tilman, B-4000 Liege, Belgium

12

$13{ }^{3}$ CART, Inorganic Analytical Chemistry, Chemistry Department, University of Liege, Allée de

14 la Chimie 3, B-6c Sart-Tilman, B-4000 Liege, Belgium

15

$16{ }^{4}$ CART, Laboratory of Food Analysis, Faculty of Veterinary medicine, University of Liège,

17 Boulevard de Colonster 20, B-43bis Sart-Tilman, B-4000 Liege, Belgium

19 Correspondence: Claude Saegerman, UREAR, Research Unit of Epidemiology and Risk 20 Analysis applied to veterinary sciences, Faculty of Veterinary Medicine, University of Liège, 21 Boulevard de Colonster, 20, B42, B-4000 Liège, Belgium

22 Email: claude.saegerman@ulg.ac.be 
24 Abstract

25 This paper provides an estimate of the furan content of Belgian foods. The objective of the 26 study was to achieve the best food chain coverage with a restricted number of samples 27 ( $\mathrm{n}=496)$. The geographic distribution, different market chains and labels, but also the 28 consumption frequencies were taken into account in the construction of the sampling plan. Weighting factors such as contamination levels, consumption frequency and diversity of food 30 items were applied to set up the model. The very low detection capabilities $\left(\mathrm{CC}_{\beta}\right)$ of the 31 analytical methods used (sub-ppb) allowed reporting of $78.2 \%$ of the overall dataset above $32 \mathrm{CC}_{\beta}$ and, in particular, $96.7 \%$ for the baby food category. The highest furan levels were found 33 in powdered roasted bean coffee $(1912 \mu \mathrm{g} / \mathrm{kg})$ with a mean value of $756 \mu \mathrm{g} / \mathrm{kg}$ for this 34 category. Prepared meat, pasta and rice, breakfast cereals, soups and baby food also showed 35 high mean furan contents ranging from 16 to $43 \mu \mathrm{g} / \mathrm{kg}$. Comparisons with contamination 36 surveys carried out in other countries pointed out differences for the same food group and 37 therefore contamination levels are related to the geographical origin of food items. Introduction

42 Furan was isolated for the first time in food in the late 70s (Maga, 1979). The first report on 43 its toxicology and carcinogenesis came out fourteen years later (National Toxicology 44 Program, 1993). In 1995, the International Agency for Research on Cancer (IARC) classified 45 it as "possibly carcinogen to humans" (group 2B). Five years later, the American National 46 Academy of Science (NAS) classified it as a narcotic (NAS, 2000). More recently, furan 47 received an increasing matter of concern since a report about its occurrence in food was 
48 published by the United State Food and Drug Administration (US-FDA) in 2004 (US-FDA,

49 2004). As a result, national and international food authorities required information about

50 levels in food, human exposure and formation pathways to be gathered (Stadler, 2007). In

51 Europe, the first report published by the European Food Safety Authority (EFSA) contained a

52 compilation of early reported data (EFSA, 2005). Later, EFSA organized the collection and

53 the centralisation of foodstuffs monitoring data from EU Member States in a European

54 database. Since 2009, EFSA published summarised reports on a regular basis (EFSA, 2009;

55 EFSA, 2010). In addition, independent and timely studies were also conducted in European

56 countries and in Asia (e.g. Reinhard et al., 2004; Zoller et al., 2007; Crews et al., 2009; Kim

57 et al., 2009; Liu et Tsai, 2010). Recently, the production of furan was described in heat-

58 processed food including home-cooked and ready-to-eat items (Crews et al., 2007; Fromberg

59 et al., 2009; Hasnip et al., 2006; Roberts et al., 2008). Other papers studied the influence of

60 vitamin $\mathrm{C}$ or fat oxidation on the generation of furan in a starch-based model (Owczarek-

61 Fendor et al., 2010a; Owczarek-Fendor et al., 2010b). Significant differences related to origin

62 and brands of products were also reported (Wegener and López-Sánchez, 2010). The authors

63 pointed out clear differences existing in the composition and preparation of final products

64 among factories and countries. As a result, country-by-country contamination studies are

65 needed for an accurate estimation of furan levels. Other studies have focused on the toxicity

66 and carcinogenicity of furan in the human diet as recently reviewed by Bakhiya and Appel

67 (2010). All these studies contributed to fulfil the lack of reliable data needed to conduct an

68 accurate risk assessment (Heppner and Schlatter, 2007).

69 Sampling strategies can follow different approaches. If the study is subjected to

70 economic constraints limiting the number of samples to analyse, then the study can only focus

71 on the most contaminated items (Crews et al., 2009; Wegener and López-Sánchez, 2010). On

72 the other hand, large numbers of samples can support exhaustive studies. As an example, 
EFSA or Food and Agriculture Organisation (FAO) collected data from national surveys to

74

75

76

77

78

combine them in a European or international database (EFSA, 2009; JECFA, 2010).

In this paper, we propose an original approach to carry out, as exhaustively as possible, a contamination assessment of the food chain with a restricted number of samples.

The methodology introduces several weighting factors with the idea to emphasize or to minimize the role of three selected parameters that we considered as essential. In this context, a pre-requisite condition was to use the same analytical method in order to avoid methods-tomethods analytical biases. In addition, the selected method was sensitive enough to minimize the number of results below the detection capability $\left(\mathrm{CC}_{\beta}\right)$.

\section{Materials and Methods}

\section{Analytical methodology}

The analysis was carried out using the method described and validated by Scholl and collaborators (Scholl et al., 2007; Scholl et al., 2009). It is a sub-room temperature on-line isotopic dilution - solid phase microextraction - GC-MS (ID-SPME-GC-MS) methodology. Briefly, samples are mashed and mixed in a cooled room kept at $+4^{\circ} \mathrm{C}$. Sample $(1 \mathrm{~g})$ was weighed into a tarred $20 \mathrm{~mL}$ headspace vial (La-Pha-Pack, Langerwehe, Germany) containing $0.4 \mathrm{~g}$ of salt (Sigma-Aldrich, St. Louis, MO, USA), and $1 \mathrm{~mL}$ of Milli- ${ }^{\circledR}$ water (Millipore, Brussels, Belgium). Rapidly, the sample was spiked with a deuterated-isotopomer $\left(\mathrm{d}_{4}\right.$-furan 98\%, Sigma-Aldrich, St. Louis, MO, USA) and air-tightly closed. Samples were prepared one by one, as fast as possible, to avoid furan loss by evaporation.

The deuterated standard used for quantification was a $100 \mathrm{pg} / \mu \mathrm{L}$ water solution daily prepared by dilution of $\mathrm{d}_{4}$-furan. The dilution was carried out in 2 steps: firstly, by addition of $10 \mu \mathrm{L}$ of $\mathrm{d}_{4}$-furan in a $20 \mathrm{~mL}$ airtight vial full of methanol (picograde, LGC-Promochem, Wesel, Germany); secondly, by introducing $4 \mu \mathrm{L}$ of the first solution in a $20 \mathrm{~mL}$ airtight vial 
98 full of Milli- $\mathrm{Q}^{\circledR}$ water. The same protocol was applied to prepare native furan (purity $>99 \%$;

99 Sigma-Aldrich, St. Louis, MO, USA) stock solution used to build up a three levels100 calibration curve with at least two replicates per level.

101 The measurement was performed with a PolarisQ ion-trap mass spectrometer 102 (Thermo-Scientific, Waltham, MA, USA) coupled to a Trace GC2000 equipped with a 103 Programmable Temperature Vaporization (PTV) injector. The chromatographic separation 104 was achieved on a PoraBond-Q (25m x $0.32 \mathrm{~mm} \times 5 \mu \mathrm{m})$ column (Varian, Palo Alto, CA, 105 USA) at $1.7 \mathrm{~mL} / \mathrm{min} \mathrm{He}(99.9997 \%$ purity, Air Products, Allentown, PA, USA) constant 106 flow. The temperature program started at $35^{\circ} \mathrm{C}$ for $2 \mathrm{~min}$, ramped at $10^{\circ} \mathrm{C} / \mathrm{min}$ to $100^{\circ} \mathrm{C}$ hold $1075 \mathrm{~min}$, followed by a $30^{\circ} \mathrm{C} / \mathrm{min}$ temperature ramp until $260^{\circ} \mathrm{C}$ hold $6 \mathrm{~min}$. Ions are produced 108 by a $70 \mathrm{eV}$ positive electron ionisation (EI) source kept at $200^{\circ} \mathrm{C}$. The acquisition was 109 recorded in selected ion monitoring mode (SIM). Ions m/z 68 and 72 were chosen for 110 quantification of furan and $\mathrm{d}_{4}$-furan, respectively. The relative intensities of both ions of the 111 furan molecule (i.e. $\mathrm{m} / \mathrm{z} 68$ and 39) and the $\mathrm{d}_{4}$-furan (i.e. $\mathrm{m} / \mathrm{z} 72$ and 42 ) shall correspond to 112 those of the calibration standard solutions to check the presence of possible interferences.

113 Furan extraction was carried out with a fully automated sub-room temperature SPME 114 integrated in a Combipal system (CTC Combipal, CTC Analytics, Zwingen, Switzerland).

115 The fibre was a $75 \mu \mathrm{m}$ Carboxen ${ }^{\mathrm{TM}}$-Polydimethylsiloxane coating (Supelco, St. Louis, MO, 116 USA). The extraction time and temperature are matrix-dependant. Temperature was set and 117 kept constant by a Peltier cooling system (CTC Analytics, Zwingen, Switzerland) during 118 extraction. Fibre desorption occurred in the injection port of the PTV kept at $230^{\circ} \mathrm{C}$ in 119 splitless mode. Finally, fibre was cleaned-up using a side oven maintained at $275^{\circ} \mathrm{C}$ under $\mathrm{He}$ 120 gentle flow. 


\section{$121 \quad$ Samples}

122 Samples were freshly purchased in several markets across Belgium according to a sampling 123 plan described below. Samples were stored at $-20^{\circ} \mathrm{C}$ or at room temperature prior to analysis 124 according to the manufacturer recommendations.

\section{Statistical tests}

126 A Welch's test was used to compare the mean furan concentration from this study with 127 several available studies having unequal variances (Dagnelie, 1998). The Bonferroni 128 correction which is a method used to address the multiple comparisons problem was also 129 used. This correction is based on the idea that if $n$ hypothesis are involved, each individual 130 hypothesis must be tested at $1 / n$ times the significance level to maintain the family wise error 131 rate. In the present study, we compared together 3 datasets at $95 \%$ confidence level. To verify 132 the null hypothesis, the calculated $P$ value must be below or equal to 0.05 . However, when 133 using the Bonferroni correction with three comparisons involved, $P$ value is reduced to 0.017 134 (Petrie and Watson, 2006).

136 Results and discussion

\section{Sampling plan construction}

138 The number of samples allocated for the furan contamination assessment was limited to 496.

139 To extract as much as possible information from this limited sampling number, three key 140 parameters were identified and selected to construct the model: contamination levels, food 141 diversity, and consumption frequency as shown in Figure 1. As the Belgian consumption 142 survey (IPH/EPI, 2006) did not include any data for baby food, the model has not been 143 applied to this specific category. The 30 baby food samples were treated separately as a 144 category itself. The 466 remaining samples were distributed over the food chain. 
145 Firstly, the food chain was divided into 36 groups (see Table I), and 10 samples were assigned 146 to each food group without any other consideration.

147 Secondly, a weighting factor based on already reported contamination levels (US148 FDA, 2004; EFSA, 2005) was applied to the number of samples to be analysed in each food 149 group. This weighting factor is within -10 and +5 samples and is only modified by a 5 150 samples step (i.e. $-10,-5,0$, or +5 samples). For instance, a +5 factor was selected for items

151 reported to be the most contaminated like coffee, baby food or crispy food. On the contrary, a $152-10$ factor was applied for items never reported as contaminated (e.g. reported as "not153 detected") such as water and fresh eggs. Between these two extreme cases, two additional 154 moderate factors, -5 and 0 , were also affected to the remaining food groups and to groups for 155 which no data were available, respectively (Table III).

156 Thirdly, frequencies of food consumption were also taken into account in this strategy.

157 Based on the Belgian national dietary survey, a weighting factor between -5 and +5 (by step 158 of 5) was directly awarded to 3 categories of consumption frequencies: highly (+5 samples), 159 moderate (no change) and little consumed (-5 samples).

160 Fourthly, a criterion relying on the diversity of food items within a group was also 161 investigated. A cut-off value based on the number of different matrices that could be included 162 within a group was applied. A weighting factor (+5) was computed on groups having a 163 number of matrices above the cut-off while it remained unchanged below that value.

164 Fifthly, the sampling plan proposal was submitted to a Belgian committee of experts, 165 all working in the field of food safety. This committee critically reviewed the proposed 166 weighting factors based on their own experience in food safety. They provided 167 recommendations to modify the third and fourth weighting factors with the final objective to 168 extract a consensus sampling plan. 
Sixthly, to discard any geographical effect, the sampling was spread over the country.

170

171

172

173

174

175

176

177

178

179

180

181

182

183

184

185

186

187

188

189

190

191

192

193

As Belgium is divided into 10 provinces, the same number of samples was randomly collected in each province.

At last, to specifically avoid a brand or a food market chain related to a province, the samples were randomly distributed over 7 to 10 food market chains depending upon the availability.

Approximately 100 different markets were visited in the country. Between 5 and 10 items were purchased in triplicate in each market.

\section{Results}

According to the authorities' recommendation (EC, 2007), three individual items of each sample were mixed and homogenized. A representative aliquot was then sampled for analysis according to the described methodology. The study only focused on raw samples in order to avoid biases from cooking and heating effects. The analytical method was developed to achieve a high sensitivity and a low $\mu \mathrm{g} / \mathrm{kg}$ detection capability $\left(\mathrm{CC}_{\beta}\right)$. As a result, $78.2 \%$ of the overall samples analysed were above $\mathrm{CC}_{\beta}$, and in particular, $96.7 \%$ of baby food samples were above $\mathrm{CC}_{\beta}$.

Results are summarized in figures $2 \mathrm{~A}$ and $2 \mathrm{~B}$. They show that furan was present in a variety of commercial foods and the levels spanned several orders of magnitude from background levels (sub-ppb) to the highest one (hundreds of ppb). The highest levels, sometimes exceeding $1000 \mu \mathrm{g} / \mathrm{kg}$, were found in coffee. Lower, but nevertheless very high levels close to $100 \mu \mathrm{g} / \mathrm{kg}$, were found in prepared meat, pasta and rice, baby food and breakfast cereals. Raw meat products, fat, fresh fruits, milk and alcohol groups showed a low mean furan content. Heat-treated foods such as roasted and/or long time-cooked items are characterized by a high furan content (Fromberg et al., 2009; Roberts et al., 2008). For foods that did not follow these cooking recipes, they are mainly classified in the low content 
194 category. As expected, the majority of samples below $\mathrm{CC}_{\beta}$ are gathered in the low levels 195 groups.

196 In addition, contamination levels are not homogeneous within a food group. They are 197 scattered from low to high concentrations depending either on the food type and/or on the 198 cooking and packaging methodology.

199 Baby food results are displayed in Figure 2 C. Items are distributed over 3 sub-groups: 200 baby food containing cereals and fruits, baby food containing meat and/or vegetables and 201 other baby food. Low contamination levels were found in the first group with a mean value 202 with $95 \%$ confidence interval of $3 \pm 5 \mu \mathrm{g} / \mathrm{kg}$. The second group exhibited a much higher 203 mean level $(65 \pm 57 \mu \mathrm{g} / \mathrm{kg})$ while the third one is somewhat an intermediate between the first 204 two groups $(23 \pm 73 \mu \mathrm{g} / \mathrm{kg})$. In the present study, the results clearly indicate that the level of 205 furan in baby food is linked to the food composition.

\section{Comparison with previous surveys}

207 Several contamination assessments were conducted around the world. Two of them were 208 selected for a comparison as their data are of the public domain. The present results were then 209 compared to data reported by Switzerland (Reinhard et al., 2004; Zoller et al., 2007) and by 210 EFSA in 2009 (EFSA, 2009). Mean values of the highest contaminated food groups for the

211 three studies are presented in Table II. These results were compared by using the Welch's test 212 with the Bonferroni correction for statistical significance.

213 For the Coffee group, Table II shows that the null hypothesis is neither verified 214 between our study and EFSA, nor between our study and the Swiss work, nor between the 215 EFSA and the Swiss study. The result displayed by the Swiss study is several times lower 216 than the results obtained by the other groups. This difference is explained by the applied 217 methodology: the Swiss survey reports results from brewed coffee, whereas the present one 218 and the EFSA report focus on from raw coffee. Formerly, it was demonstrated by several 
219 groups that the coffee furan content is recipe-dependant (Kuballa, 2007; La Pera et al., 2009;

220 Guenther et al., 2010) and as the same methodology was not applied, these results are not 221 comparable. The alternative hypothesis shows that our mean value is nearly 2 times lower 222 than the EFSA mean value $(P<0.0001)$. This difference is linked to the results of the 223 display very high contamination levels. Only few of them were analysed in the present survey and they did not display such high levels. This seems to be consecutive to the differences linked to the roasting process as previously highlighted by Guenther and co-workers (Guenther et al., 2010).

For the Prepared meat group, the null hypothesis was verified for the comparison between our survey and EFSA, and between our survey and the Swiss study. Significant differences $(P=0.0002)$ were observed when comparing Swiss and EFSA surveys mean values. The mean value measured in the present study was included within the same range of values calculated in the two other studies. The Swiss mean value was nearly twice higher than EFSA mean value. One can assume there is an influence of "local products" and/or "local preparation". Several studies showed that furan concentration is related to the exact composition and preparation recipe of food items (Crews et al., 2007; Roberts et al., 2008; Wegener et al., 2010). Other authors suggested that the exact food composition and recipe are geographically related (Merchant et al., 2006; Pennington, 2008). This phenomenon presents a higher impact on "composed" or "prepared" food items rather than on basic products.

For the Soups group, the null hypothesis was only verified when comparing our survey to the EFSA study. The comparison between the present study and the Swiss work showed significant differences $(P<0.0015)$, as well as the comparison between EFSA and ReinhardZoller mean values. In both cases, the concentration reported by the Swiss survey is more than twice as high. Two hypotheses can be drawn in relation with the composition of the food 
244 item. Firstly, it could be linked to the influence of the local production on the furan content.

245 Secondly, the food group sampling can induce biased results.

246 For the Breakfast cereals group, the null hypothesis is not verified between our study

247 and the Swiss or the EFSA survey. In each case, our contamination level is more than twice

248 higher than the level reported by the Swiss and EFSA surveys. Within this group, the major

249 contribution comes from roasted products. Therefore, there are few differences from country

250 to country. Nevertheless, the null hypothesis was not verified probably because the Swiss and

251 EFSA surveys also included other types of cereal products that are not roasted, thus

252 presenting lower contamination levels.

253 For the Baby food group, the null hypothesis is verified for all the comparisons. The

254 mean values of the three surveys are similar at a 95\% confidence interval. It can be explained

255 by the scattering of data in this group (i.e. the standard deviation is equal or higher than its

256 corresponding mean value for each group). As already shown in figure $2 \mathrm{C}$, the baby food

257 group is very large and can be divided into three sub-groups containing respectively: meat

258 and/or vegetables, fruits and cereals, and other.

259 For the Pasta and Rice group, the comparison was not possible as this category was

260 not present in the other studies.

261 In general, our results are in accordance with the EFSA survey, but in a lesser extend

262 with the Swiss study when using a Welch's test taking into account the Bonferroni correction

263 ( $P<0.017)$. For each mean value, except for coffee, the corresponding $P$ is under 0.01 . The

264 statistical significance seems to be related to the local products. Therefore, this is one more

265 clue to support that the European survey is "very large", and provides results comparable to

266 local surveys, but that local surveys provide more accurate data, useful to carry out more

267 precise risk assessments. 
268

269

270

271

272

273

274

275

276

277

278

279

280

281

282

283

284

285

286

287

288

289

290

291

292

\section{Conclusions}

The study shows that almost the whole food chain is contaminated with furan. Roasted foods (such as breakfast cereals or coffee), long time cooking-foods or foods contain sauces (such as prepared meat compared to raw meat) are the most contaminated. Fat, raw meat, milk, alcohol and fresh fruits are the less contaminated items. It suggests that the heat processing conditions are crucial for the contamination levels. Baby foods results display a high disparity and can be distributed over 3 groups according to the food composition.

The methodology developed for this assessment is fit-for-purpose. One can carry out an evaluation of mean levels, ground levels and critical items using a limited number of samples. Such evaluation usually includes a very high number of samples to be exhaustive or only focuses on the known critical items. The methodology used is useful to determine some information on background levels, mean levels and on the most contaminated items. It is also an overall screening of the food chain that can be used for several purposes like risk assessment, identification of the critical items, estimation of the ground level, or identification of some formation critical components.

In addition, our results are consistent with studies already published (Reinhard et al., 2004; Zoller et al., 2007; EFSA, 2009). However, when comparing data, one should especially be careful with the way of reporting data (furan in coffee). On the other hand, statistical differences could mainly be attributed to the exact food composition, which is linked to the geographical origin of the food item. This tends to proof that local surveys induce less variability than international surveys. Precise risk assessments could be better obtained using a local approach especially in order to determine the more risky or exposed population.

In conclusion, the proposed methodology successfully fulfils our requirements that were: combining the results that can be obtained using a screening survey to the results 
293 obtained using an exhaustive methodology with a limited number of samples. Therefore the

294 proposed methodology is a fast and cost-effective methodology useful to carry out a "pseudo-

295 exhaustive” contamination assessment across the food chain.

296 Acknowledgments

297 This study was funded by the Belgian Federal Public Service of Health, Food Chain Safety

298 and Environment (contract RT 06/01 FURA). The authors also want to acknowledge

299 Christine Vinkx, Ria Nouwen and Isabel DeBoosere from the Federal Public Service of

300 Health, Food Chain Safety and Environment, Katleen Baert from the Belgian Agency for

301 Food Safety (AFSCA), Norbert Dekimpe, Bruno De Meulenear and An Adams from the

302 University of Gent and Guy Maghuin-Rogister from the University of Liege for their

303 participation to the committee of experts.

304

305 References:

306 Bakhiya N and Appel KE. 2010. Toxicity and carcinogenicity of furan in human diet. Arch

$307 \quad$ Toxicol. 84(7):563-578.

308 Crews C., Castle L. 2007. A review of the occurrence formation and analysis of furan in heat-

309 processed foods. Trends in Food Science and Technology. 18:365-372.

310 Crews C, Hasnip S, Roberts DPT and Castle L. 2007. Factors affecting the analysis of furan

311 in heated foods. Food Addit Contam. 24(S 1):108-113

312 Crews C., Roberts D., Lauryssen S., Kramer G. 2009. Survey of furan in foods and coffees

313 from five European Union countries. Food Additives \& Contaminants: Part B.

$314 \quad 2(2): 95-98$

315 Dagnelie P. 1998. Statistique théorique et appliquée. Inférence statistique à une et à deux

316 dimensions. (Tome 2), De Boek University, Brussels, Belgium, pp. 659. 
317 EFSA. 2005. Report of the Scientific Panel on Contaminants in the food chain on provisional

318 findings on furan in foods. Corrected report published on 7 November 2005. The

319 EFSA Journal. 137:1-20.

320 EFSA. 2009. Technical report of EFSA prepared by Data Collection and Exposure Unit

321 (DATEX) on "Monitoring of furan in food". The EFSA Scientific Report. 304:1-23.

322 EFSA. 2010. Update of results on the monitoring of furan levels in food. EFSA Journal.

$323 \quad 8(7): 1702$.

324 European Commission. 2007. Commission Regulation (EC) $N^{\circ} 333 / 2007$ laying down the

325 methods of sampling and analysis for the official control of the levels of lead,

326 cadmium, mercury, inorganic tin, 3-MCPD and benzo(a)pyrene in foodstuffs. Official

327 Journal of the European Union. L88/29-L88/38.

328 Food and Drug Administration. 2005. CFSAN/Office of Plant and Dietary Foods.

329 Determination of furan in foods, May 7, 2004; Updated June 2, 2005. Available at the

$330 \quad$ URL address:

331 http://www.fda.gov/Food/FoodSafety/FoodContaminantsAdulteration/ChemicalConta

332 minants/Furan/ucm078400.htm.

333 Fromberg A., Fagt S., Granby K. 2009. Furan in heat processed food products including home

334 cooked food products and ready-to-eat products. In: Report of the EFSA

335 CFP/EFSA/DATEX/2007/03 project. The National Food Institute, the Technical

336 University of Denmark. Available at URL address:

337 http://www.efsa.europa.eu/fr/scdocs/doc/1e.pdf.

338 Guenther H., Hoenicke K., Biesterveld S., Gerhard-Rieben E., Lantz I. 2010. Furan in coffee:

339 pilot studies on formation during roasting and losses during production steps and

340 consumer handling. Food Additives \& Contaminants. 27(3):283-290. 
341 Hasnip S., Crews C., Castle L. 2006. Some factors affecting the formation of furan in heated

342 foods. Food Additives and Contaminants. 23(3):219-227.

343 Heppner C.W., Schlatter J.R. 2007. Data requirements for risk assessment of furan in food.

$344 \quad$ Food Additives \& Contaminants. 24(S1):114-121.

345 IARC. 1995. Monographs on the Evaluation of Carcinogenic Risks to Humans. 63:393.

346 Summaries and evaluations. Available at the URL address:

347 http://www.inchem.org/documents/iarc/vol63/furan.html.

348 IPH/EPI. 2006. Belgian Consumption Food Survey nr 1 - 2004. Reports n²006-014.

349 Available at the URL address: http://www.iph.fgov.be/epidemio/epien/index5.htm

350 JECFA. 2010. Summary report of the seventy-second meeting of JECFA. Available at URL

351 address: http://www.who.int/foodsafety/chem/summary72_rev.pdf.

352 Kim T.K., Lee Y.K., Kim S., Park Y.S., Lee K.G. 2009. Furan in commercially processed

353 foods: four-year field monitoring and risk assessment study in Korea. Journal of

354 Toxicology and Environmental Health: Part A. 72:1304-1310.

355 Kuballa T. 2007. Furan in coffee and other foods. Journal für Verbraucherschutz und

$356 \quad$ Lebensmittelsicherheit. 2(4):429-433.

357 La Pera L., Liberatore A., Avellone G., Fanara S., Dugo G., Agozzino P. 2009. Analysis of

358 furan in coffee of different provenance by head-space solid phase microextraction gas

359 chromatography-mass spectrometry : effect fo brewing procedures. Food Additives \&

$360 \quad$ Contaminants. 26(6):786-792.

361 Liu Y.T., Tsai S.W. 2010. Assessment of dietary furan exposures from heat processed foods

362 in Taiwan. Chemosphere. 79(1):54-59.

363 Maga JA. 1979. Furans in foods. CRC Crit Rev Food Sci Nutr. 11(4):355-400.

364 Merchant A.T., Dehghan M.. 2006. Food composition database development for between

365 country comparisons. Nutrition Journal. 5(2). 
366 NAS. 2000. Spacecraft Maximum Allowable Concentrations for Selected Airborne

367 Contaminants. 4(B14):307-329. Available at the URL address:

368 http://fermat.nap.edu/books/0309067952/html/307.html.

369 NTP. 1993. Toxicology and carcinogenesis studies of furan (CAS No. 110-00-9) in F344/N

370

371

372

373

374

375

376

377

378

379

380

381

382

383

384 rats and B6C3Fl mice (gavage studies). NTP Technical Report No. 402., U.S. Department of Health and Human Services, Public Health Service, National Institutes of Health, Research Triangle Park, NC. Available at the URL adress: http://ntp.niehs.nih.gov/ntp/htdocs/LT_rpts/tr402.pdf.

Owczarek-Fendor A., De Meulenaer B., Scholl G., Adams A., Van Lancke F., Yogendrarajah P., Eppe G., De Pauw E., Scippo M.-L., De Kimpe N. 2010 Furan formation from vitamin $\mathrm{C}$ in a starch-based model system: Influence of the reaction conditions. Food Chem. 121(4):1163-1170.

Owczarek-Fendor A., De Meulenaer B., Scholl G., Adams A., Van Lancke F., Yogendrarajah P., Uytterhoeven V., Eppe G., De Pauw E., Scippo M.-L., De Kimpe N. 2010 Importance of fat oxidation in starch-based emulsions in the generation of the process contaminant furan. J. Food and Agric. Chem. 58(17):9579-9586.

Pennington J.A.T. 2008. Applications of food composition data: Data sources and considerations for use. J. Food Compos. Anal. 21:S3-12.

Petrie A., Watson P. 2006. Statistics for Veterinary and Animal Science, Second Edition. Blackwell Publishing., pp. 312.

Reinhard H., Sager F., Zimmermann H., Zoller O. 2004. Furan in Foods on the Swiss Market - Method and Results. Mitt. Lebensm. Hyg. 95:532-535.

388 Roberts D., Crews C., Grundy H., Mills C. 2008. Matthews W., Effect of consumer cooking 389 on furan in convenience foods. Food Additives \& Contaminants: Part A. 25(1):25-31. 
390 Stadler R.H. 2007. Update in the progress in acrylamide and furan research. Food Additives

391 \& Contaminants. 24(S1):1-2.

392 Scholl G., Scippo M.-L., Maghuin-Rogister G., De Pauw E., Eppe G. (2007). Developement

393 of a sub-room temperature SPME-GC-MS method for the analysis of furan in food. In:

394 Book of abstracts, $3^{\text {rd }}$ International Symposium on Recent Advances in Food Analysis.

$395 \quad$ p. 307.

396 Scholl G., Scippo M.-L., Focant J.-F., De Pauw E., Eppe G. (2009). Validation of a sub-room

397 temperature ID-SPME-GC-MS method for the analysis of furan if food. In: Book of

398 abstracts, $4^{\text {th }}$ International Symposium on Recent Advances in Food Analysis. p. 407.

399 Wegener J-W and Lopez-Sanchez P. 2010. Furan levels in fruit and vegetables juices,

400 nutrition drinks and bakery products. Analytica Chimica Acta. 672(1-2, Sp. Iss.

$401 \quad$ SI):55-60.

402 Zoller O., Sager F., Reinhard H. 2007. Furan in food: Headspace method and product survey.

$403 \quad$ Food Additives \& Contaminants. 24(S1):91-107.

404 
405

406

407

408

409

410

411

412

413

414

415

416

417

418

419

420

421

422

\section{Table and figure caption}

Table I. Groups of food items in the Belgian food chain

Table II. Comparison of the results of three European surveys for the most contaminated food groups using a two tailed-Welch $t$ test. The limit of significance was defined as $P<0.001$.

Legend:

$\mathrm{n}$ : number of samples in the group; Mean: mean concentration in $\mu \mathrm{g} * \mathrm{~kg}^{-1}$ or $\mu \mathrm{g}^{*} \mathrm{~L}^{-1}$ ; SD: Standard Deviation in $\mu \mathrm{g}^{*} \mathrm{~kg}^{-1}$ or $\mu \mathrm{g}^{*} \mathrm{~L}^{-1}$; ND: data unavailable; a: significantly higher than the EFSA study; b: significantly lower than the EFSA study; c: significantly higher than the Swiss study; d: significantly lower than the Swiss study; e: significantly higher than the present study; f: significantly lower than the present study.

Table III. Weighing factors used for the furan sampling across the food chain

Legend: for explanation, see the section 3.1. Sampling plan construction 
1

2

3

4

5

6

7

8

9

10

11

12

13

14

15

16

17

18

19

20

21

22

23

24

25

26

27

28

29

30

31

32

33

34

35

36

37

38

39

40

41

42

43

44

45

46

47

48

49

50

51

52

53

54

55

56

57

58

59

60

423 Figure 1.

424 Title: Sampling plan for the estimation of the furan contamination across the Belgian food 425 chain

426

427

428

429 Figure 2.

430 Title: Furan contamination levels across the Belgian food chain

431 Legend: $2 \mathrm{~A}$ and $2 \mathrm{~B}$, all the food chain; $2 \mathrm{C}$, baby foods (details)

432

433

434 
Table I. Groups of food items in the Belgian food chain

\begin{tabular}{|ll|ll|}
\hline$(1)$ & Spirits & $(2)$ & Beer \\
\hline$(3)$ & Bread & $(4)$ & Breakfast cereals \\
\hline$(5)$ & Cereal based products & $(6)$ & Cheese \\
\hline$(7)$ & Coffee & $(8)$ & Cooking fat \\
\hline$(9)$ & Edible offal & $(10)$ & Egg \\
\hline$(11)$ & Fish & $(12)$ & Fish based products \\
\hline$(13)$ & Fresh meat & $(14)$ & Fruit \\
\hline$(15)$ & Fruit juices & $(16)$ & Goats and rabbits \\
\hline$(17)$ & Light Soft Drink & $(18)$ & Meat \\
\hline$(19)$ & Meat based products & $(20)$ & Milk and dairy products \\
\hline$(21)$ & Other & $(22)$ & Pasta and rice \\
\hline$(23)$ & Potatoes & $(24)$ & Poultry \\
\hline$(25)$ & Sauce & $(26)$ & Seafood \\
\hline$(27)$ & Soft Drink & $(28)$ & Soup and vegetable juices \\
\hline$(29)$ & Soy based products & $(30)$ & Spreading fat \\
\hline$(31)$ & Tea & $(32)$ & Vegetarian food \\
\hline$(33)$ & Vegetables & $(34)$ & Water \\
\hline$(35)$ & Wine & $(36)$ & Yoghurts and Pudding \\
\hline
\end{tabular}


Table II. Comparison of the results of three European surveys for the most contaminated food groups using a two tailed-Welch $t$ test. The limit of significance was defined as $P<0.001$.

\begin{tabular}{lccccccccc}
\hline & \multicolumn{3}{c}{ Belgian Survey } & \multicolumn{3}{c}{ EFSA (2009) } & \multicolumn{3}{c}{ Swiss (2004) } \\
& n & Mean & SD & n & Mean & SD & n & Mean & SD \\
\hline Coffee & 25 & $756^{\mathrm{b}, \mathrm{c}}$ & 666 & 398 & $1476^{\mathrm{c}, \mathrm{e}}$ & 1292 & 111 & $36^{\mathrm{b}, \mathrm{f}}$ & 35 \\
Prepared meat & 44 & 35 & 38 & 65 & $22^{\mathrm{d}}$ & 28 & 49 & $49^{\mathrm{a}}$ & 44 \\
Pasta \& Rice & 12 & 43 & 39 & ND & ND & ND & ND & ND & ND \\
Baby Food & 42 & 35 & 45 & 985 & 25 & 27 & 350 & 28 & 28 \\
Breakfast Cereals & 16 & $31^{\mathrm{a}, \mathrm{c}}$ & 25 & 99 & $14^{\mathrm{f}}$ & 22 & 11 & $9^{\mathrm{f}}$ & 9 \\
Soups & 13 & $16^{\mathrm{d}}$ & 16 & 198 & $24^{\mathrm{d}}$ & 28 & 50 & $39^{\mathrm{e}, \mathrm{a}}$ & 31 \\
\hline
\end{tabular}

Legend:

$\mathrm{n}$ : number of samples in the group

Mean: mean concentration in $\mu \mathrm{g} * \mathrm{~kg}^{-1}$ or $\mu \mathrm{g} * \mathrm{~L}^{-1}$

SD: Standard Deviation in $\mu \mathrm{g}^{*} \mathrm{~kg}^{-1}$ or $\mu \mathrm{g}^{*} \mathrm{~L}^{-1}$

ND: data unavailable

a: significantly higher than the EFSA study

b: significantly lower than the EFSA study

c: significantly higher than the Swiss study

d: significantly lower than the Swiss study

e: significantly higher than the present study

f: significantly lower than the present study 
Table III. Weighing factors used for the furan sampling across the food chain

\begin{tabular}{|c|c|c|c|c|c|}
\hline Food groups & $\begin{array}{l}\text { Base number of } \\
\text { samples }\end{array}$ & $\begin{array}{l}\text { Weighting factor } 1: \\
\text { reported contamination } \\
\text { level }\end{array}$ & $\begin{array}{l}\text { Weighting factor 2: } \\
\text { consumption } \\
\text { frequency }\end{array}$ & $\begin{array}{l}\text { Weighting factor } \\
\text { 3: food group } \\
\text { diversity }\end{array}$ & $\begin{array}{l}\text { Total number of } \\
\text { samples }\end{array}$ \\
\hline Baby food & 30 & - & 5 & 10 & 45 \\
\hline Bread & 10 & - & - & 5 & 15 \\
\hline Breakfast cereals & 10 & - & - & 5 & 15 \\
\hline Cereal based products & 10 & - & - & 10 & 20 \\
\hline Cooking fat & 10 & - & -5 & 5 & 10 \\
\hline Edible offal & 10 & $-\quad+2$ & -5 & - & 5 \\
\hline Egg & 10 & -10 & - & - & 0 \\
\hline Fish & 10 & 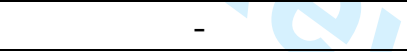 & -5 & 5 & 10 \\
\hline Fish based products & 10 & - & $\Delta$ & - & 10 \\
\hline Fresh meat & 10 & - & 2 & - & 10 \\
\hline Meat & 10 & - & - & 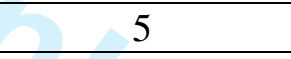 & 15 \\
\hline Meat based products & 10 & - & - & $2=$ & 15 \\
\hline Milk and dairy products & 10 & -5 & - & 5 & 10 \\
\hline Other & 10 & 5 & 5 & + & 25 \\
\hline Pasta and rice & 10 & - & - & 5 & 15 \\
\hline Potatoes & 10 & - & - & 5 & 15 \\
\hline Poultry & 10 & - & -5 & 5 & 10 \\
\hline Sauce & 10 & - & - & 5 & 15 \\
\hline
\end{tabular}




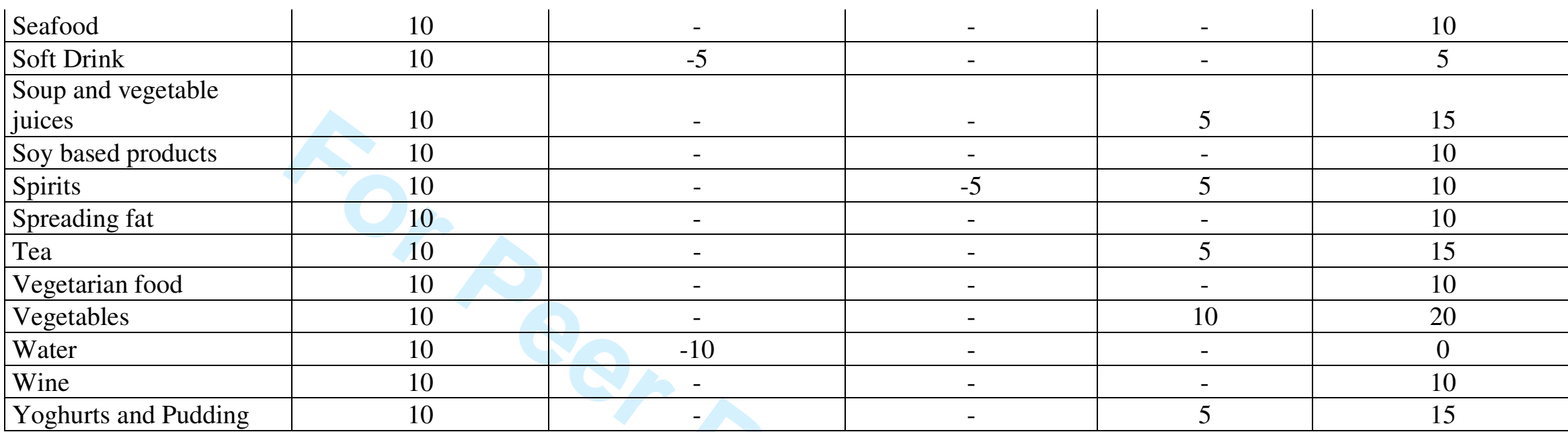

Legend: for explanation, see the section 3.1. Sampling plan construction 
Number of food

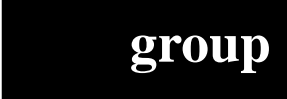

Food chain distribution:

Random sampling over 7 to

11 market chain (upon availability)

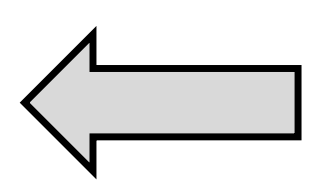

Geographical distribution:

Random sampling of 50 samples per province
Weighting factor 3: Matrix diversity

$\mathbf{S}$
27
28
29
30
31
32
33
34
35
36
37
38
39
40
41
42


Fig. 2 A

Furan concentration $\left(\mu \mathrm{g}^{*} \mathrm{~kg}^{-1}\right.$ or $\left.\mu \mathrm{g}^{*} \mathrm{~L}^{-1}\right)$

Coffee $(n=25)$

Tea $(n=15)$

Soft Drinks $(n=15)$

Beer $(n=15)$

Wine $(n=10)$

Spirits $(n=10)$

Milk and dairy based drink ( $n=17)$

Dairy based products $(n=17)$

Cheese $(n=15)$

Fruits $(n=19)$

Fruit juices $(n=16)$

Soups $(n=13)$

Vegetables $(n=21)$
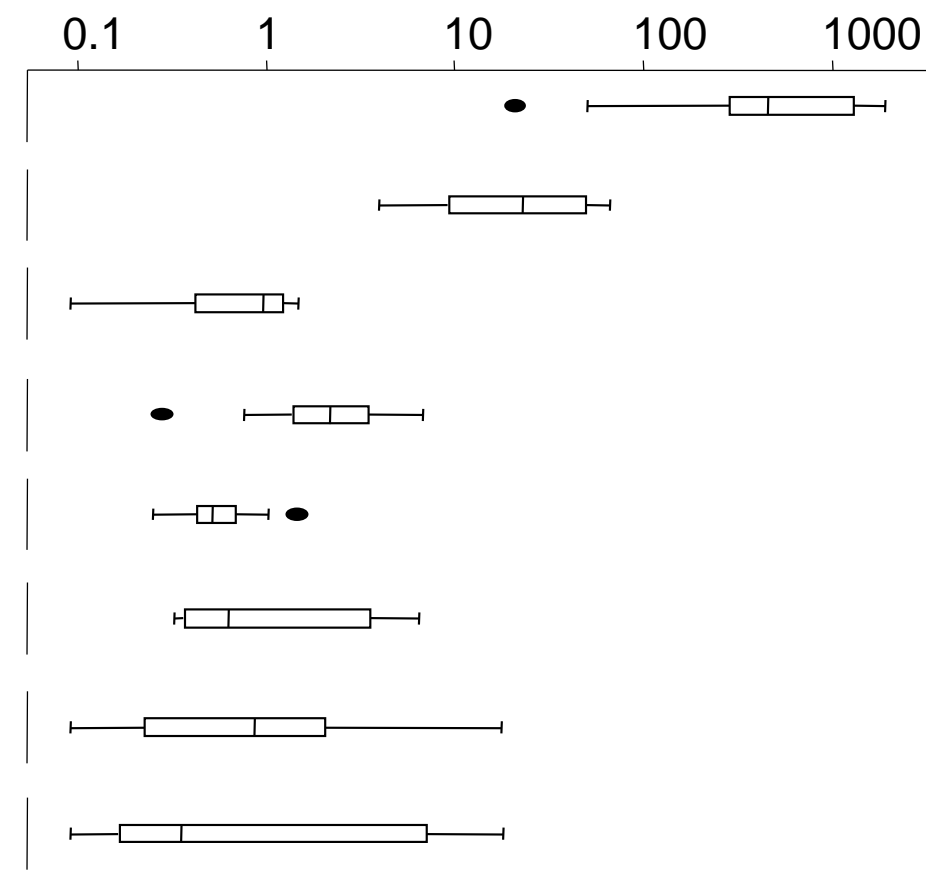

Starchy roots and potatoes $(n=15)$

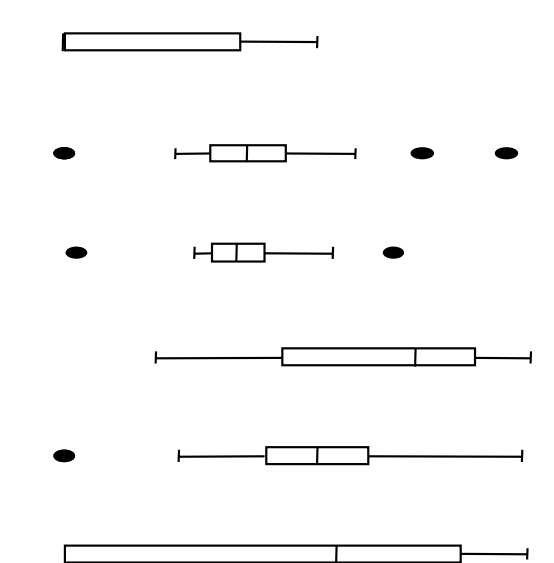


Bread $(n=15)$

Breakfast cereal $(n=16)$

Cereal based products $(n=22)$

Pasta and rice $(n=12)$

\section{Furan concentration $\left(\mu \mathrm{g}^{\star} \mathrm{kg}^{-1}\right.$ or $\left.\mu \mathrm{g}^{\star} \mathrm{L}^{-1}\right)$}

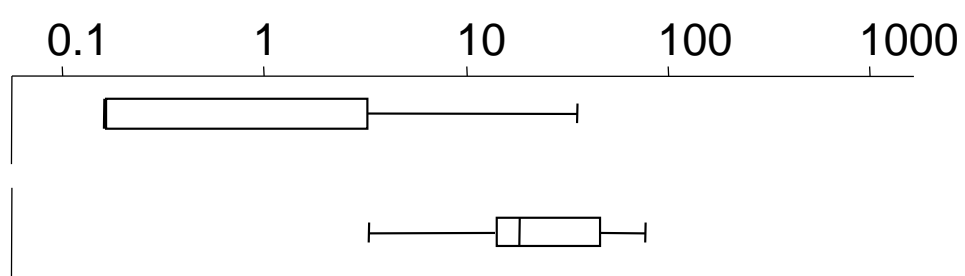

Raw meat $(n=16)$

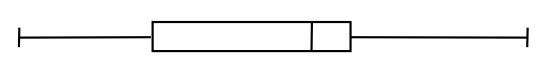

Prepared meat $(n=29)$

Processed meat $(n=19)$

Meat substitutes $(n=11)$

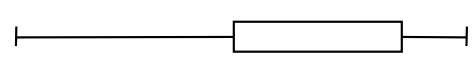

Fats $(n=21)$

Fish and seafood $(n=32)$

Baby food $(n=42)$

Miscellaneous $(n=40)$
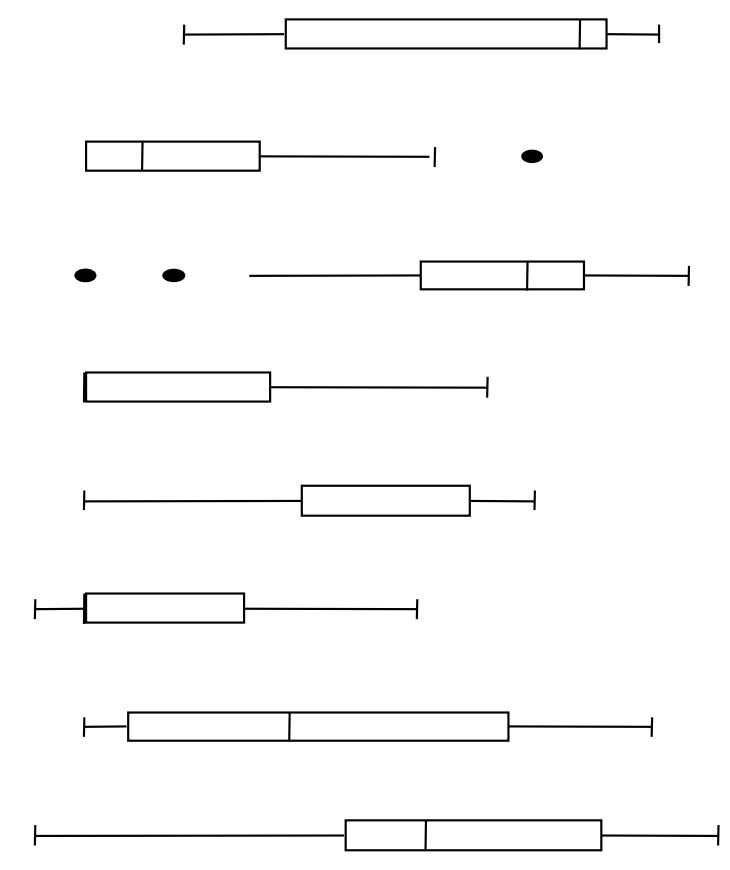
Fig. 2 C

Fruits and Cereals $(n=20)$

Meat and/or Vegetables $(n=18)$

Furan concentration $\left(\mu \mathrm{g}^{*} \mathrm{~kg}^{-1}\right.$ or $\left.\mu \mathrm{g}^{*} \mathrm{~L}^{-1}\right)$

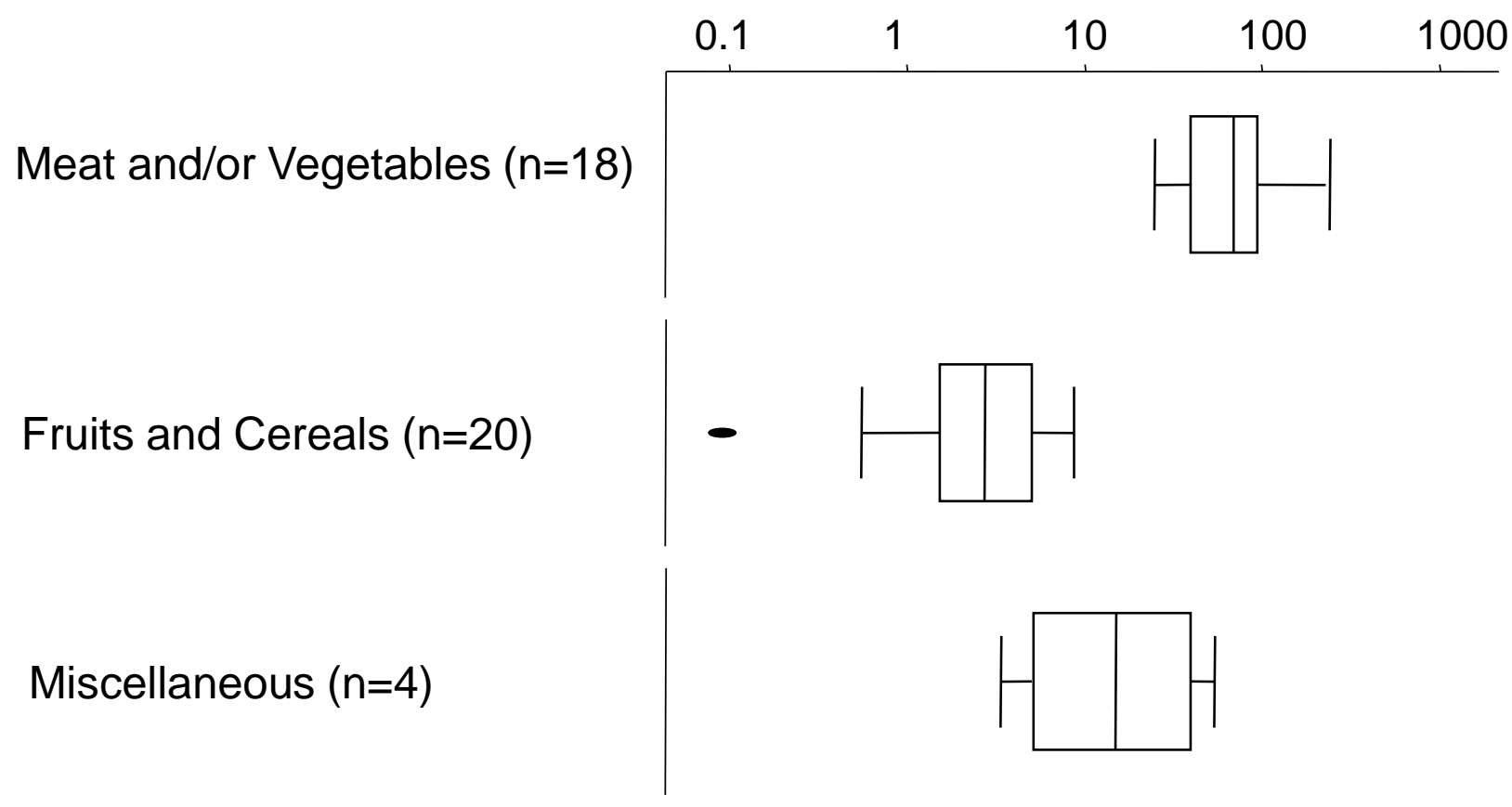

\section{Legend:}

- Outlier(s)

Maximum

$75^{\text {th }}$ percentile

Median

$25^{\text {th }}$ percentile

Minimum 